\title{
7
}

\section{LA VIEJA Y LA NUEVA POLÍTICA. LIBERTAD, PODER Y DISCURSO}

\author{
Julio De Zan \\ Jorge Baudino Ediciones/UNSAM Edita, \\ Buenos Aires, 2013, 319 páginas. \\ ISBN 978-987-1788-17-0
}

Fernando Bahr

Este reciente libro de Julio De Zan, versión aumentada y considerablemente modificada de la que publicó hace veinte años bajo el título que hoy es subtítulo, se propone «volver a pensar la política desde nuestro propio lugar, con ayuda de los clásicos y de algunos pensadores contemporáneos, para contribuir al nacimiento de una nueva política» (p. 10), política que el autor interpreta convincentemente próxima, «como los destellos que prometen el alumbramiento de un nuevo día».

Con vistas a cumplir esa tarea, De Zan organiza su estudio en torno a los tres conceptos que componen el «silogismo de lo político»: el poder como tema central, la libertad como su presupuesto y el discurso como el elemento procedimental que enlaza los dos anteriores. Hobbes lo hizo de manera semejante, señala el autor, pero desde una semántica y una lógica que desde hace tiempo han quedado obsoletas y que sólo se sostuvieron encerrándose en sí mismas y rehuyendo todo contacto con el movimiento que define el mundo de la vida social.

Es preciso, pues, volver a analizar y resignificar el silogismo de lo político. ¿Qué quiere decir «libertad» en el contexto de tal silogismo? La primera parte del libro se concentra en esta cuestión. Se distinguen así dos puntos de vista: la libertad como ausencia de impedimentos externos o libertad negativa y la 
libertad como autonomía realizada en la ley o libertad positiva. El liberalismo enfatiza la primera perspectiva; la democracia es el régimen de la segunda. Se trata de dos dimensiones de la misma libertad, señala De Zan, de la libertad "concreta y verdadera» en términos de Hegel; sin embargo, eso no quita que haya una inevitable tensión entre ellas y que su conciliación sea uno de los problemas fundamentales de la teoría política (p. 31). Estos conceptos de libertad, en efecto, implican valoraciones distintas de lo público y lo privado $y$, en consecuencia, de las relaciones entre la sociedad civil y el Estado. Para entenderlos mejor en su despliegue, por lo tanto, el autor lleva a cabo una historia conceptual de la distinción entre sociedad y Estado desde la filosofía política griega hasta Gramsci. Primero (Capítulo II) lo hace desde una interpretación estándar, heredera de la modernidad; luego (Capítulo III), a partir de la reconstrucción del sentido de lo político en $\mathrm{H}$. Arendt, centrada en la idea de la antigua polis griega, y de la redefinición del concepto contemporáneo de la sociedad civil, inspirado en J. Habermas.

Arendt y quienes piensan con ella, empero, no quieren hacer la historia de un olvido, o, en todo caso, quieren que esa historia ayude a ver una presencia: la de la sociedad civil, con cuyo concepto se piensa un campo «que es transversal a la de la distinción entre lo público y lo privado» (p. 91), que no admite ser totalizado como un macrosujeto («pueblo», "proletariado») y que se define esencialmente por su pluralidad. He aquí el espacio de los nuevos sujetos de lo político; tercer dominio intermedio o central, escribe De Zan, que no quiere ni el acceso al poder del Estado ni la acumulación de capital y donde en realidad se construye la libertad política y el poder democrático.

La sociedad civil es entonces el principal protagonista de la escena política contemporánea. Ella significaría por sí misma el retorno de lo político a sus fuentes originarias, la reconciliación de poder y libertad después del secuestro a que fue sometido el primero por el aparato estatal de la modernidad. Una verdadera revolución impensada hace algunas décadas, dice el autor, que, aunque no pueda prescindir del Estado y de los partidos políticos, sí es capaz de enfrentar y doblegar pacíficamente a los aparatos del poder centralizado imponiéndoles una agenda de reclamos que no pueden ignorar. Se trata de un hecho, y acaso del destello de otro futuro para las democracias occidentales, todas ellas carentes hoy de legitimación política, su recurso vital. 
En la introducción, De Zan se preguntaba «¿cuál es la fuente, el origen o el principio constitutivo del poder?» (p. 13). Ahora conocemos la respuesta. La fuente, el origen o el principio constitutivo del poder político es, o se encuentra en, la sociedad civil. Es decir, si, como se debe, pensamos la política antes de la institucional estatal y de todo sistema jurídico, encontraremos allí, en el espacio público de la sociedad civil, la piedra fundante. Si ésta ha desaparecido, o languidece, si la institución que debería expresarla se alimenta a sí misma, es como si la institución matrimonial prescindiera del amor o la institución eclesiástica de la religiosidad (p. 76). Lo que queda es la cáscara vacía, la pura estructura de fuerza sostenida por los fusiles, la costumbre o la venalidad.

En estos casos se trata de fuerza, no de poder. La diferencia entre tales términos es fundamental, y la segunda parte del libro, la más larga, se ocupará especialmente de explicarla. El punto de contraste al respecto lo ofrece el pensamiento de Max Weber. Dos elementos destaca De Zan en la filosofía política de Weber; el primero, que el poder parece identificarse «con la fuerza que se impone en una relación de lucha o de guerra» (p. 124); el segundo, que ese concepto, propio del ámbito económico, no sirve para la comprensión del poder político pues supone ya la institución estatal. A pesar de toda su influencia en el pensamiento político del siglo XX, o precisamente por ello, hay que dejar pues a Weber buscando un nivel anterior y más fundamental de la constitución política. Tal es el contexto en el que reaparece Hannah Arendt.

Arendt, en efecto, a diferencia de Weber, piensa el poder político en su especificidad distinguiéndolo de la fuerza e incluso estableciendo una relación inversamente proporcional entre ellos: cuanto más fuerza se utiliza hacia el interior de un cuerpo político, más significativa se vuelve la señal de impotencia; eso es lo que sucede, precisamente en el estado tiránico. Para Arendt, además, otra vez a diferencia de Weber, el poder no es medio sino fin en sí mismo y pertenece a la constitución misma del sujeto social y de lo político; son el discurso público y el actuar juntos los que lo producen performativamente; no reside naturalmente en ningún lado, aun cuando el Estado tenga el patrimonio de la fuerza.

Establecida ya una definición más adecuada de poder político en el Capítulo IV, a partir del contraste entre Weber y Arendt, el Capítulo V examina la estructura dialéctica de la relación de poder recuperando las categorías móviles de mando 
y obediencia. Esta vez el punto de apoyo no es Arendt, quien se niega a considerar tales categorías en la relación política, sino principalmente Hegel. De Zan muestra en tal sentido, primero, que las concepciones modernas no han sabido reconocer esa dialéctica como una relación viva, dinámica y reversible de la interacción entre los hombres, y, segundo, que la filosofía contemporánea, ya libre de la perspectiva de un pensamiento centrado en el sujeto, sí ha podido hacerlo a partir del concepto de teoría de la acción comunicativa. El capítulo termina con dos secciones — «Poder político y «poder económico»" y «La profesión del poder» - especialmente interesantes por sus alusiones a la historia argentina.

El Capítulo VI vuelve a situarnos en el plano teórico de la filosofía política contemporánea. Primero, para aclarar las nociones de «republicanismo», "comunitarismo» y «liberalismo»; segundo, para rebasar este debate introduciendo conceptos, como el de "communitas», que no se dejan pensar dentro de él y para abordar los problemas de legitimación de la democracia liberal representativa; tercero, para analizar otras concepciones hoy renovadas como la democracia plebiscitaria de Carl Schmitt y la teoría de la hegemonía de Gramsci y del postmarxismo (Mouffe, Laclau). Todos estos caminos conducen de alguna manera a la sección final del capítulo, esto es, al concepto de «democracia deliberativa» desarrollado por Jürgen Habermas, concepto que se distingue de los anteriores, entre otras cosas, porque la toma de decisiones no se rigen por la simple regla de la mayoría sino por «el principio del discurso y la deliberación en los espacios públicos, formales, como el Parlamento y sobre todo en los espacios no formales de la sociedad civil» (p. 259). Para De Zan, en la teoría de la democracia deliberativa, en tanto institucionalización del estado deliberativo de la sociedad y del diálogo crítico, racional, con participación igualitaria, en todos los niveles de las estructuras de poder, se encontraría «lo único que merece hoy el nombre de democracia».

El Capítulo VI cierra un trayecto del libro que comentamos; el trayecto de un rostro del poder, podríamos decir. Sin embargo, «una teoría crítica del poder no puede cerrarse como una concepción sistemática que pretenda ser comprensiva de la multifacética y siempre ambigua realidad de este fenómeno» (p. 263). El poder siempre tiene otros rostros, otros relatos, otras teorías. Consciente de ello, De Zan dedica el último capítulo a abrir una nueva perspectiva: la de las diversas relaciones de poder que obran en distintos campos de la vida social 
tal como ha sido diseccionada por Michel Foucault en textos como «lgualdad, territorio y población» o «El nacimiento de la biopolítica».

Al igual que los seis capítulos anteriores de este libro, el capítulo dedicado a Foucault es claro, preciso. Julio De Zan sabe cómo guiar al lector novato por los meandros de la filosofía y sabe cómo discutir con el especialista; sabe cómo traducir los léxicos propios de cada corriente o autor a un lenguaje comprensible; sabe cómo aplicar los conceptos puros al análisis de los acontecimientos de la historia. Por todo ello, y por muchos otros detalles a los que ninguna reseña puede ser fiel, no podemos más que recomendar su lectura. 